\title{
Using CT-scanning technology to quantify damage of the stem-boring beetle, Aphanasium australe, a biocontrol agent of Hakea sericea in South Africa
}

\section{Candice L. Lyons, Muofhe Tshibalanganda \& Anton Du Plessis}

To cite this article: Candice L. Lyons, Muofhe Tshibalanganda \& Anton Du Plessis (2019): Using CT-scanning technology to quantify damage of the stem-boring beetle, Aphanasium australe, a biocontrol agent of Hakea sericea in South Africa, Biocontrol Science and Technology, DOI: 10.1080/09583157.2019.1682518

To link to this article: https://doi.org/10.1080/09583157.2019.1682518

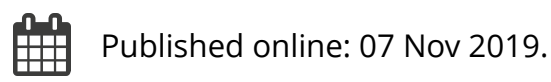

\section{Submit your article to this journal $\square$}

山 Article views: 20

Q View related articles ¿

View Crossmark data〔 


\title{
Using CT-scanning technology to quantify damage of the stem-boring beetle, Aphanasium australe, a biocontrol agent of Hakea sericea in South Africa
}

\author{
Candice L. Lyons ${ }^{\mathrm{a}, \mathrm{b}}$, Muofhe Tshibalanganda ${ }^{c}$ and Anton Du Plessis (1) ${ }^{c}$

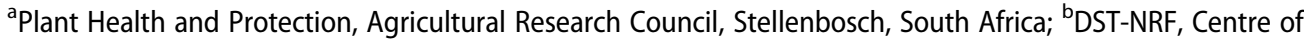 \\ Excellence for Invasion Biology, Stellenbosch University, Matieland, South Africa; 'Central Analytical Facility, \\ Stellenbosch University, Stellenbosch, South Africa
}

\begin{abstract}
The stem-boring beetle, Aphanasium australe was introduced into South Africa in 2001 for biocontrol of Hakea sericea. It has a twoyear life cycle, the majority of which is spent within the basal stem and roots of its host plant. Damage assessments indicate that $A$. australe is capable of killing $7-10 \%$ of trees in a Hakea stand. However, how much internal damage, and number of insects that are required to cause significant damage or death of the plant, is not known. Here, we used a novel technique - X-ray micro computed tomography (microCT) - to quantify damage in dead and live trees. We also used the technique to assess whether microCT is feasible as a means to determine percentage emergence and survival of larvae/pupae within Hakea stumps. Results showed that the technique can be used successfully to quantify damage, and that felled live trees had significantly less damage than felled dead trees. The amount of internal damage was significantly influenced by the number of insects that emerged, and by the overall size of the trees. MicroCT was able to determine with $100 \%$ accuracy the survival of insects that were either inside stumps or had emerged at the time of scanning. A complex suite of factors are responsible for death or survival of trees once infested with the biocontrol agent, and percentage internal damage to trees is not the only factor that dictates whether or not a tree will succumb to the effects of the stem-borer.
\end{abstract}

\section{ARTICLE HISTORY}

Received 21 June 2019

Accepted 11 October 2019

\section{KEYWORDS}

Biocontrol; CT-scan; micro-CT; Aphanasium; Hakea sericea

\section{Introduction}

The Western Cape Province of South Africa is home to one of seven of the World's biodiversity hotspots, in the form of the Fynbos Biome (Myers, Mittermeier, Mittermeier, da Fonseca, \& Kent, 2000), characterised by high species endemism. This region faces threats from climate change, water abstraction, fires and invasive species encroachment and competition (e.g. van Wilgen \& RIichardson, 1985; van Wilgen et al., 2010). One of the most prolific invaders in mountain fynbos is Hakea sericea, or silky hakea. This species

CONTACT Candice L. Lyons candice.lyons@hotmail.com $\cong$ Plant Health and Protection, Agricultural Research Council, Private Bag X5017, Stellenbosch 7599, South Africa; DST-NRF, Centre of Excellence for Invasion Biology, Stellenbosch University, Matieland 7602, South Africa 
originates from Australia and was introduced into South Africa in the 1800s as a hedging plant (Neser \& Fugler, 1978). It forms dense, impenetrable stands, with adult trees growing in excess of six to eight metres, and retaining up to 30000 fruit capsules, each with two winged seeds (Gordon, 1999). The tree is serotinous and releases its seeds from the hard fruit capsule following the fire, or death of the tree (Gordon, 1999). Hakea sericea is a member of the Protea family and outcompetes indigenous protea species, which are an integral part of the Fynbos ecosystem, through competition for resources.

To date, management of this invasive species has been in the form of mechanical clearing and biological control, with the latter being considered the most cost-effective means to managing large populations and spread thereof. The biological control programme against $H$. sericea began in the 1960 s and was the first of its kind to implement seedfeeding agents against a woody shrub. The programme is one of the longest running globally, and especially in South Africa. Currently, the programme employs several insect agents and a pathogenic fungus in management of $H$. sericea. These include, the seed-feeding weevil, Erytenna consputa, which targets the younger fruit capsules; the seed-feeding moth, Carposina autologa, which targets the harder, older fruits; the flowerbud-feeding weevil, Dicomada rufa, which targets flowering shoots and young leaves; Cydmaea binotata, the shoot-feeding weevil; and Aphanasium australe, the stem-boring beetle. In addition, in the 1990s, a mycoherbicide was developed from an indigenous fungus, Colletotrichum acutatum, after noticeable impacts of this fungus were observed on the tree. This fungus infects plants via a wound, and can potentially kill adult trees above the site of infection.

All insect agents used for biocontrol against $H$. sericea, originate from Australia, along with the host plant which has become invasive in South Africa and elsewhere. Insects introduced for biological control have undergone stringent testing in quarantine prior to release. Releases were done at different times since the initiation of this biocontrol programme, to supplement the management strategy at the time (Gordon, 1999). The stemboring beetle, $A$. australe, was one of the last agents to be introduced for this programme, with initial releases having taken place in 2001 (Gordon \& Fourie, 2011). The female lays her eggs at the base of the tree, and up to 150 eggs per female, have been observed (Gordon, 2003); the larvae burrow into the trunk where they begin feeding on plant tissue, forming several burrows or tunnels, and sufficiently high levels of internal damage can lead to death of the tree. The beetle has a two-year life cycle, with the majority of this time being spent as larvae/pupae, inside Hakea stems/trunks. For this reason, populations are very susceptible to fires, a regular occurrence in the Fynbos biome and greater Western Cape region.

Unfortunately, due to the nature of this system, it is virtually impossible to determine infield what the levels of infestation per tree are, and what the relative damage is internally to each tree. Although destructive sampling is used in felling trees, physically sectioning stumps to determine the number of larvae and the levels of internal damage, is virtually impossible, without risking the development and survival of the insect population. With the advent of X-ray microtomography (also referred to as CT scanning or microCT) technology, and its applications to a broader field of research, these in-field shortcomings now become less of setback for a system such as that of A. australe and H. sericea, since individuals are still able to emerge from felled and scanned stumps and can thus be returned to the field to boost populations. Furthermore, CT scanning allows one to investigate the internal 
structure thoroughly, with improved accuracy, and in great detail. Very few studies, if any, have used microCT technology to assess the damage inflicted on trees by insects, although several studies have discussed the applications of this technology to the broader biological field, particularly in herpetological research in the context of evolutionary biology and morphology (see Broeckhoven \& du Plessis, 2018 for review). A review of the methodology for microCT applied to biological samples is presented in detail in (Du Plessis, Broeckhoven, Guelpa, \& Le Roux, 2017). In the forestry industry, this technique is used to identify internal flaws or defects, prior to logs being sent to the sawmill for processing (e.g. Schmoldt, 1996). MicroCT is also an important, non-destructive way to analyse irreplaceable artefacts and fossils (Matthews \& Du Plessis, 2016).

Despite the fact that twenty years have passed since the first releases of A. australe, many populations have been destroyed by fires, and remaining populations of the insect are believed to be limited. Concerns have arisen that the species is not performing as well as initially expected due to potential mortality in field. Thus far, the impact of A. australe in field is unclear, and the population level required to cause significant damage is unknown. In this paper, we aim to determine what the in-field levels of impact of A. australe is within sites in the Western Cape, while at the same time, trying to assess population levels, based on emergence rates and microCT scanning results. We also aim to determine what the level of infectivity and levels of damage for dead trees versus live trees is, in an effort to quantify the potential long-term impacts of this beetle to the biocontrol field. We aim to answer the following questions: 1 . Do dead trees have more internal damage than live trees? Can the damage be quantified using MicroCT techniques?; 2. Does damage correlate with the number of insects that emerged from the stumps, or with the number of insects internally visible from scanning techniques?; 3. Can this technology be used to assess a survival rate or emergence rate of insects?

\section{Materials and methods}

\section{Hakea specimens}

In 2015, an investigation into the level of abundance of $A$. australe in $H$. sericea trees was initiated at Slanghoek, close to Worcester in the Western Cape. Eight trees were selected, based on visible signs of $A$. australe infestation and were subsequently felled. In total, six healthy-looking trees, and two dead trees were felled and their stumps removed from the soil, with lateral roots intact. Towards the end of 2017, prior to an additional planned collecting trip, the site was lost to a massive wildfire. Consequently, a second site was chosen, close to Caledon (Genadendal) where an additional eight trees were felled. No dead trees were present at this site, but trees that were felled $(N=8)$ in 2017 all had visible signs of infection with the stem-boring beetle. A notable sign of infestation with the beetle is a saw-dust like exuvia from the base of the tree, caused by the internal feeding action of larvae within the stump (Gordon \& Fourie, 2011), and a 'gummy' exudate caused from burrowing of larvae into the tree upon egg hatching. Trees were grouped into either 'alive' $(n=14)$ or 'dead' $(n=2)$ categories. Those trees that were dead were clearly killed by the stem-borer, as evidenced from emergence holes present at the base of the trunk. Unfortunately, due to the fire and the drought that persisted since late 2015, it was not possible to increase the sample size of the number of dead 
trees felled and used in this study. In total 16 trees were felled, and scanned using microCT techniques.

\section{Scanning of stumps}

MicroCT scans were done in two stages - in 2015/6 and 2018 - at the Stellenbosch CT facility using from $150-180 \mathrm{kV}$ and up to $100 \mu \mathrm{A}$ for X-ray generation, with an isotropic voxel size of $0.1 \mathrm{~mm}$ (Du Plessis, Le Roux, \& Guelpa, 2016). A total of 3200 projection Xray images were acquired during a full rotation of the sample, which was mounted in a cardboard tube for stability during scanning. Reconstruction was performed using system-supplied Datos software. Volume data was visualised and analysed further using Volume Graphics VGSTUDIO MAX 3.0. In particular, the damaged areas were segmented using a series of morphological image tools to separate internal and external air, despite many damaged cavities being connected to the exterior. After segmentation the defect analysis tool was used to quantify the volumetric damage.

\section{Statistical analyses}

To assess differences in internal damage between live and dead trees, a non-parametric Mann Whitney U Test for unequal sample sizes was run. A multiple regression was used to determine how percentage damage was influenced by the size of the trees, and the number of larvae that either emerged, or were visible, from scans. All analyses were run in Statistica (v. 13.5). MicroCT was also used to assess the survival of the stemborer by calculating a percent survival based on the number of adults that had emerged, as well as those that were visibly alive or dead, inside the stumps. Only 2015 data was used for this assessment as stumps were sent for scanning prior to the emergence in 2015, but post-emergence in 2018 .

\section{Results}

Dead and live trees differed significantly in terms of the amount of internal damage that was observed by the microCT technology $(Z=-2.14 ; P<0.05)$, with dead trees having significantly greater internal median damage when compared to live trees (Figure 1).

Results from the multiple regression showed that the defect volume in live versus dead trees was significantly influenced by both the number of insects that had emerged, and the overall size of the tree $\left(P<0.05 ; R^{2}=0.39 ; F(2,1615)=524,18\right)$. For live trees, the general trend was an increase in damage with an increase in number of insects that had emerged (Figure 2). The amount of internal damage also increased with the size of the tree (Figure 3).

Number of insects that emerged from felled $H$. sericea trees correlated with the number that were visible from microCT scans (Table 1) (Plates 1 and 2).

\section{Discussion}

This is the first study to use microCT technology to assess the survival of a stem-boring beetle inside trees and internal damage caused by the agent to host plants. In total, 


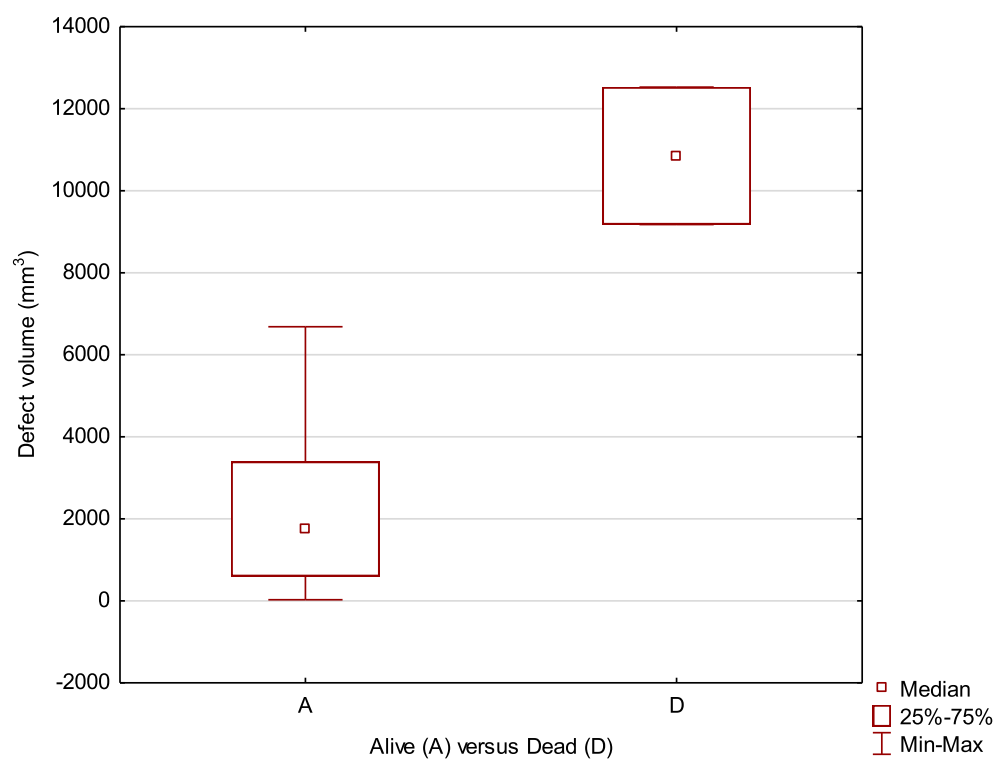

Figure 1. Box plot showing median amount of damage (defect volume) inflicted by the stem-boring beetle, $A$. australe. The $25 \%$ and $75 \%$ confidence intervals and the minimum and maximum damage observed for live (A) and dead (D) $\mathrm{H}$. sericea trees that were felled and sent for scanning in the microCT facility are also depicted.

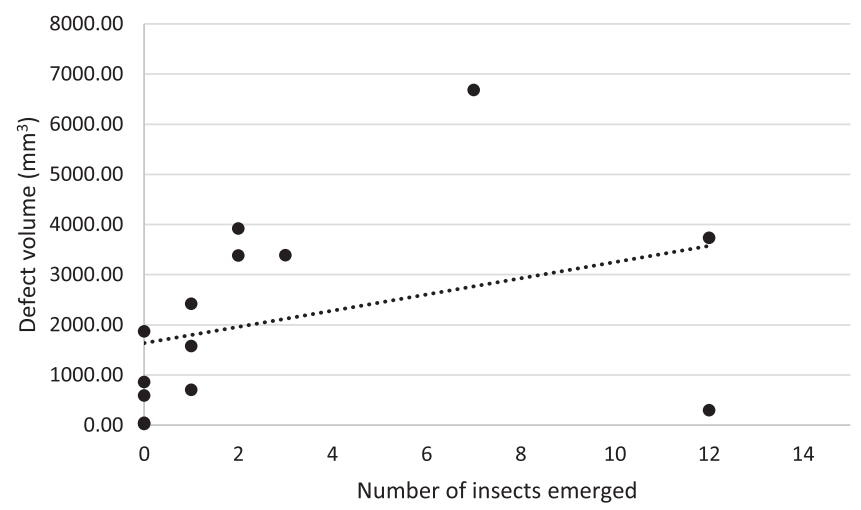

Figure 2. Relationship between the number of insects that emerged from felled live trees of $H$. sericea containing A. australe, and the amount of internal damage (defect volume) that was visible from microCT scans.

A. australe has been released in varying abundance at over twenty sites since its initial introduction in 2001/2. The majority of these sites have been lost to fires or clearing, with little information available on the beetle's dispersal ability from the remaining sites where it is known to have established. Population levels at the established sites are also uncertain, although data from the current study now indicate a healthy population at what is thought of as the most-abundant existing site, Genadendal (Caledon). MicroCT scans of the felled trees in this study show that the population of A. australe at the two 


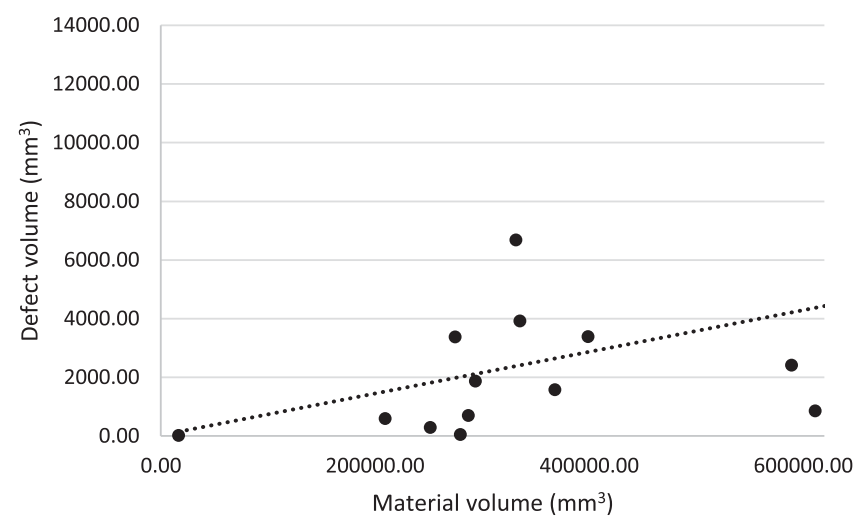

Figure 3. Relationship between the size of $H$. sericea trees (material volume) versus the amount of internal damage (defect volume) observed through use of MicroCT technology.

Table 1. Number of $A$. australe beetles visible from scans of $H$. sericea and number that emerged and were subsequently released, showing percentage accuracy of the scanning technology for samples collected in 2015, and percentage survival of the stem-borer in field.

\begin{tabular}{lcccc}
\hline Sample number & Number visible from scans & Number emerged and released & \% accuracy & \% Survival of beetle \\
\hline 2015_1 & 1 & 1 & 100 & 100 \\
2015_2 & 0 & 0 & 100 & 100 \\
2015_3 & 2 & 2 & 100 & 100 \\
2015_4 & 2 & 2 & 100 & 100 \\
2015_5 & 0 & 0 & 100 & 100 \\
2015_6 & 8 & 7 & 100 & 87.5 \\
2015_7 & 0 & 0 & 100 & 100 \\
2015_8 & 12 & 12 & 100 & 100 \\
\hline
\end{tabular}
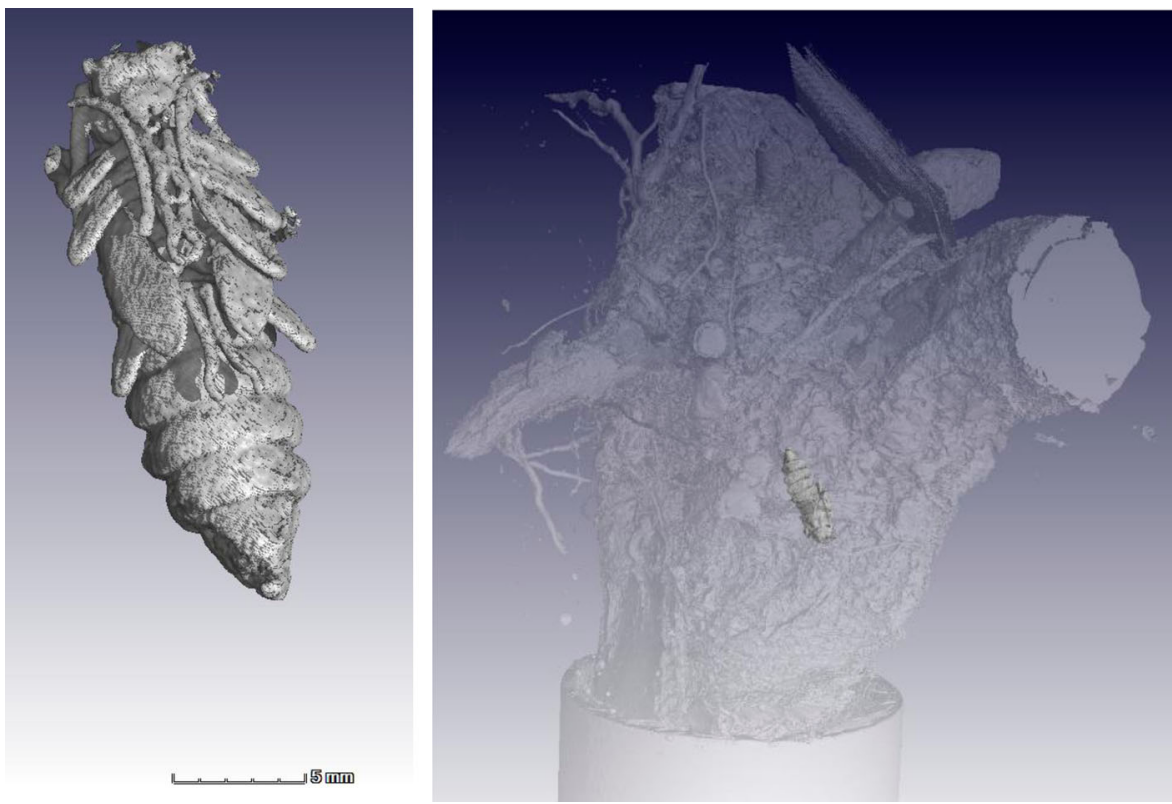

Plate 1. Example of microCT scan of a $H$. sericea stump containing an Aphanasium australe pupa. 


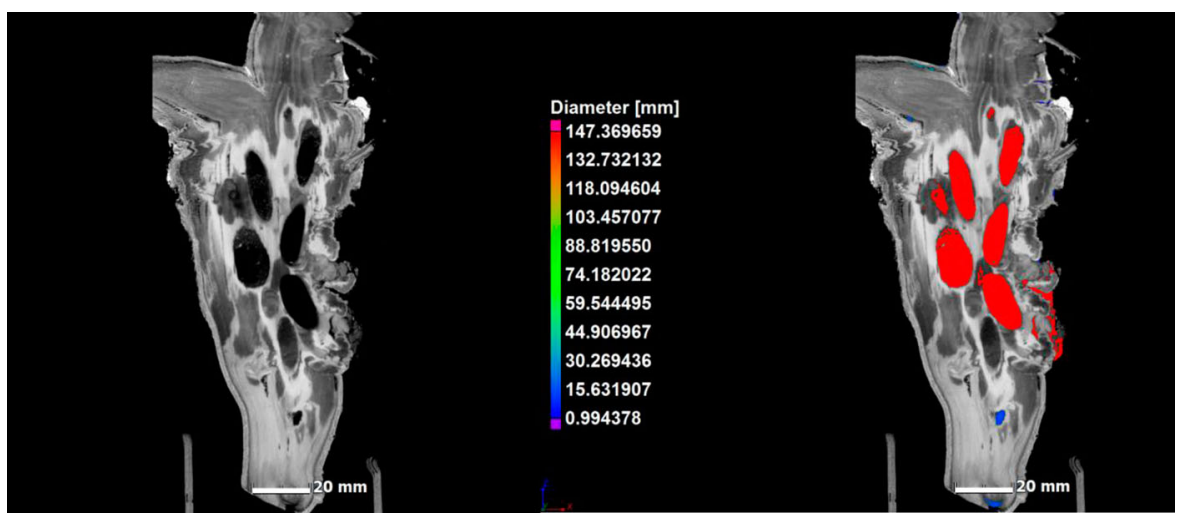

Plate 2. A 2D image of a CT slice of a $H$. sericea stump used to quantify extent of internal damage (red) using Volume Graphics VGSTUDIO MAX 3.0.

study sites in the Western Cape, appear to be increasing steadily, with a near one hundred percent emergence and survival rate of larvae and pupae. Given the significant hazards faced by this species in terms of fires, and the loss of a prominent site to fire several years back, the evidence of an increasing or stable population of insects at the next most-abundant field site, bodes well for the future of this programme.

As a biocontrol agent, $A$. australe causes significant internal damage to $H$. sericea trees, as viewed through microCT technology. This technique has certainly confirmed that the level of damage required to cause death to the tree is largely dependent on both the number of insects present internally; and also, on the overall size of the tree Larger trees appear to be able to tolerate more insects and more internal damage before they face the possibility of death.

Once a tree is infested with the stem-borer, several factors may influence whether the beetle will damage the tree sufficiently to cause its death. For a tree to be killed, the beetle will need to impact the nutrient transport mechanism of the plant (xylem and phloem vascular tissues) (e.g. Hoffmann \& Moran, 1991). Even though stem-boring insects have the potential to kill their host plant, as in the case of Sesbania punicea and the biocontrol programme initiated against this weed in South Africa (see Hoffmann \& Moran, 1991), there are several examples where stem-boring insects have variable impacts on their host plants. In the annual weed, Parthenium hysterophorus the stem-boring weevil, Listronotus setosipennis does not produce obvious signs of damage to the plant (Dhileepan, 2003), while a different stem-boring insect used for the same weed in New Zealand, Listronotus bonariensis, causes significant damage which is, however, difficult to recognise (Goldson, Proffitt, \& Baird, 1998). Although the actual larval feeding may not cause the death of the plant in our case, the action of larval tunnelling within trees weakens the tree to the extent that strong winds (frequent in the Western Cape region) may result in trees being blown over (Gordon, 2003). Furthermore, the burrowing action and subsequent emergence of the adult beetles following their two-year lifecycle, opens up cavities near the base of the tree. These cavities or 'injury sites' could act as entrance sites for the pathogenic indigenous fungus (Colletotrichum acutatum) currently used in the biocontrol programme against $H$. sericea and occurring naturally in the landscape. In this way, the 
synergistic relationship between fungus and insects may very well result in the death of an increased proportion of the weed population in the Western Cape. This emphasises the need for further releases and redistribution of both fungus and Aphanasium australe at sites with high infestation of $H$. sericea, and a detailed investigation into the interaction between these two agents.

\section{Conclusions}

MicroCT was successfully able to quantify levels of damage inside felled H. sericea trees, and, despite low sample sizes, damage was correlated with whether or not trees were dead or alive prior to felling. It was clear how many insects were present inside samples, and we were successfully able to determine a level of survival and emergence of $A$. australe from samples that were processed. Due to low sample size, it is not yet possible to accurately assess how many insects are required before a tree dies. MicroCT is considered a nondestructive technique to assess levels of insect infestation, or levels of damage inside trees, and provides an effective and practical use of resources and time.

\section{Acknowledgements}

The Drakenstein Trust and DEA:NRMP are thanked for funding. Keith Appollis, Abraham Adonis and Sivuyisiwe Zondani are thanked for field assistance. John Hoffmann and Fiona Impson are thanked for discussion and editing of drafts.

\section{Disclosure statement}

No potential conflict of interest was reported by the authors.

\section{Funding}

This work was supported by Department of Environmental Affairs; Drakenstein Trust.

\section{ORCID}

Anton Du Plessis (iD http://orcid.org/0000-0002-4370-8661

\section{References}

Broeckhoven, C., \& du Plessis, A. (2018). X-ray microtomography in herpetological research: A review. Amphibia-Reptilia, 39, 377-401.

Dhileepan, K. (2003). Current status of the stem-boring weevil Listronotus setosipennis (Coleoptera: Curculionidae) introduced against the weed Parthenium hysterophorus (Asteraceae) in Australia. Biocontrol Science and Technology, 13, 3-12.

Du Plessis, A., Broeckhoven, C., Guelpa, A. \& Le Roux, S. G. (2017). Laboratory x-ray micro-computed tomography: A user guideline for biological samples. Gigascience. doi:10.1093/gigascience/ gix027

Du Plessis, A., Le Roux, S. G., \& Guelpa, A. (2016). The CT scanner facility at Stellenbosch University: An open access X-ray compute tomography laboratory. Nuclear Instruments and Methods in Physics Research: Section B, 42-49. doi:10.1016/J.NIMB.2016.08.005 
Goldson, S. L., Proffitt, J. R., \& Baird, B. D. (1998). The bionomics of Listronotus bonariensis (Coleoptera: Curculionidae) in Canterbury, New Zealand. Bulletin of Entomological Research, $88,415-423$.

Gordon, A. J. (1999). A review of established and new insect agents for the biological control of Hakea sericea Schrader (Proteaceae) in South Africa. African Entomology Memoir, 1, 35-43.

Gordon, A. J. (2003). Biology and the host-range of the stem-boring beetle, Aphanasium australe, a promising agent for the biological control of Hakea sericea in South Africa. BioControl, 48, 113 122.

Gordon, A. J., \& Fourie, A. (2011). Biological control of Hakea sericea Schrad. \& J.C. Wendl and Hakea gibbosa (Sm.) Cav. (Proteaceae) in South Africa. African Entomology, 19, 303-314.

Hoffmann, J. H., \& Moran, V. C. (1991). Biological control of Sesbania punicea (Fabaceae) in South Africa. Agriculture, Ecosystems and Environment, 37, 157-173.

Matthews, T., \& du Plessis, A. (2016). Using X-ray computed tomography analysis tools to compare the skeletal element morphology of fossil and modern frog (Anura) species. Palaeontol Electron, 19(1), 1-46.

Myers, N., Mittermeier, R. A., Mittermeier, C. G., da Fonseca, G. A. B., \& Kent, J. (2000). Biodiversity hotspots for conservation priorities. Nature, 403, 853-858.

Neser, S., \& Fugler, S. R. (1978). Silky hakea. In C. H. Stirton (Ed.), Plant invaders: Beautiful but dangerous (pp. 76-79). Cape Town: Department of Nature and Environmental Conservation of the Cape Provincial Administration.

Schmoldt, D. L. (1996, May 8-11). CT imaging, data reduction, and visualization of hardwood logs. Proceedings of the 24th Annual Hardwood Symposium, North Carolina. 1996.

van Wilgen, B. W., Forsyth, G. G., de Klerk, H., Das, S., Khuluse, S., \& Schmitz, P. (2010). Fire management in mediterranean-climate shrublands: A case study from the Cape fynbos, South Africa. Journal of Applied Ecology, 47, 631-638.

van Wilgen, B. W., \& Richardson, D. M. (1985). The effects of alien shrub invasions on vegetation structure and fire behaviour in South African fynbos shrublands: A simulation study. Journal of Applied Ecology, 22, 955-966. 